\title{
WOOD-INHABITING MACROFUNGAL ASSEMBLAGES IN 43-YEAR-OLD REGENERATING WET EUCALYPTUS OBLIQUA L'HÉR. FOREST
}

\author{
by Genevieve M. Gates, David M. Carpenter, David A. Ratkowsky and Patrick J. Dalton
}

\author{
(with six text-figures and five tables)
}

\begin{abstract}
Gates, G.M., Carpenter, D.M., Ratkowsky, D.A. \& Dalton, P.J. 2011 (9:xii): Wood-inhabiting macrofungal assemblages in 43-year-old regenerating wet Eucalyptus obliqua L'Hér. forest. Papers and Proceedings of the Royal Society of Tasmania 145: 65-76. https://doi.org/10.26749/rstpp.145.65 ISSN 0080-4703. School of Plant Science, University of Tasmania, Private Bag 55, Hobart, Tasmania 7001, Australia (GMG*, DMC, PJD); School of Agricultural Science, University of Tasmania, Private Bag 54, Hobart, Tasmania 7001, Australia (DAR). Author for correspondence. Email: Genevieve.Gates@utas.edu.au
\end{abstract}

\begin{abstract}
This study focuses on the diversity and ecology of wood-inhabiting macrofungal species assemblages in a regenerating tall, wet, native Eucalyptus obliqua forest in southeast Tasmania, 43 years after natural and anthropogenic disturbances. Two plots subjected to "clearfell, burn and sow" silviculture were compared with two other nearby plots that had experienced wildfire. A total of 90 species was identified from 619 macrofungal records during six fortnightly visits between May and July 2010. The plots with abundant live Pomaderris apetala trees in the understorey (i.e., those at Edwards Rd) had markedly different macrofungal assemblages from those with no or with sparse Pomaderris apetala (i.e., at Hartz Rd). This study provided evidence that a 43-year-old regenerating forest maintains a core of common wood-inhabiting macrofungal species irrespective of type of disturbance. Furthermore, species most frequently observed in older forests in Tasmania can also occur in younger managed forests if biological legacies such as large diameter wood, well-decayed wood, large living trees and a diversity of tree species remain after silvicultural treatment.
\end{abstract}

Key Words: wood-inhabiting macrofungi, Eucalyptus obliqua, Pomaderris apetala, wildfire, managed forests, Tasmania.

\section{INTRODUCTION}

Maintaining wood-decay fungal diversity is an essential part of a productive forest ecosystem, and many studies have addressed the effect of anthropogenic disturbance on assemblages of wood-inhabiting macrofungal species in forests, especially in the Northern Hemisphere (e.g., Bader et al. 1995, Czederpiltz et al. 1999, Christensen et al. 2004, Heilmann-Clausen \& Christensen 2005). Nevertheless, forest conservation programs of many countries still completely neglect fungi as an official conservation priority or even acknowledge their existence (Heilmann-Clausen \& Vesterholt 2008).

The fruit bodies are the most obvious sign of the presence of a wood-inhabiting fungus. Macrofungal fruiting bodies on wood perform important habitat functions in their own right, providing food and shelter for a myriad of faunal species (Pavoir-Smith 1960, Pielou \& Verma 1968, Schigel 2007, Robinson et al. 2008). Some polypore species are considered to be indicators of old-growth forest and important for the persistence of specialist insects (Komonen 2001). Macrofungal fruiting bodies can provide habitat and food for other fungal species inhabiting dead wood (Jonsson et al. 2005). Nutrients (Ca, Fe, K, Mn, N, P, Zn) can be exported via fruit bodies from the wood and returned to the forest floor by animals ingesting the fruit body, or by the senescence of the fruit body, which, for most fungal species takes only a few days to several weeks (Vogt et al. 1981, Harmon et al. 1994, Buchanan et al. 2001).

Esseen et al. (1997) and Penttilä et al. (2006) suggest that many of the negative effects of forest management activities on wood-inhabiting macrofungal species are a result of the simplification of the structure of these managed stands compared with natural unmanaged stands, as trees in managed regrowth forests are younger, smaller diameter, with smaller branches. Forest management also greatly alters the disturbance dynamics and results in a reduction and fragmentation of mature and old forests. The decline in the amount of dead wood, fragmentation of remaining natural dead wood habitats, and a change in the composition of the dead wood in current habitats have had dramatic effects on wood-inhabiting fungal communities (Heilmann-Clausen \& Vesterholt 2008). Developing effective management protocols to minimise losses of macrofungal species depends on knowledge of what is an acceptable habitat loss or population reduction. This implies knowledge of the biological function and, in particular, the ecology of the individual fungal species (Arnolds 2001, Watling 2005).

In Australia, studies specifically on the ecology and diversity of wood-inhabiting macrofungi are few (seeFryar $e t$ al. 1999, Hopkins et al. 2011, Gates et al. 2011c) although wood-inhabiting macrofungi are generally documented as part of general macrofungal surveys (e.g., Packham et al. 2002, Robinson \& Tunsell 2007, Robinson et al. 2008) without any attempt to analyse the data further. McMullanFisher (2008) undertook substrate fidelity analysis in her cryptogam study and concluded that there were suites of fungi with preferences either for small wood $(\leq 5 \mathrm{~cm}$ diam.) or for large wood (>5 cm diam.).

The most widespread forest type in Tasmania is wet Eucalyptus obliqua L'Hér. forest (Public Land Use Commission 1996). At maturity, E. obliqua can frequently reach heights of over $70 \mathrm{~m}$ (Kirkpatrick \& Backhouse 1981). Wet E. obliqua forests in Tasmania need disturbance to regenerate (Gilbert 1959). 'The most common type of natural disturbance is wildfire, the frequency and intensity of which are important in determining the nature of the future forest environment (Wells \& Hickey 1999). A fire interval ranging from 20 to 100 years will result in the development of a wet sclerophyll forest community, whereas longer intervals of between 100 to 350 years result in mixed forest communities (Gilbert 1959, Wells \& Hickey 1999). Fire intervals of greater than 400 years cause a maturation of rainforest understorey species to form a dominant canopy 
which restricts eucalypt recruitment and after the senescence of the older eucalypts creates a characteristic temperate rainforest (Gilbert 1959, Jackson 1968).

The current silvicultural method in the wet eucalypt forests of southern Tasmania is "clearfell, burn and sow" (CBS) on rotations of 80-100 years (Hickey et al. 2001). The CBS method removes all living trees of value and a high intensity fire is then applied to the area which incinerates the logging slash waste and produces an ash bed which is highly favourable to eucalypt seed germination. This method was considered to mimic the effects of a natural wildfire disturbance which is essential in the regeneration of tall, wet eucalypt forests in Tasmania (Jackson 1968). This operation, however, leaves very few (if any) biological legacies such as stags, coppicing burnt trees or remnant patches of living forest (Lindenmayer \& McCarthy 2002). It is suggested that CBS operations more likely mimic an extreme natural wildfire event or a succession of wildfires at short intervals, as described in Jackson (1968).

The macrofungal species that colonise after fire disturbance in Tasmania are very different from the group of species present in a predisturbed forest (Gates et al. 2005, 2009). The post-disturbance colonisation of substrates by macrofungal species is likely to occur more rapidly after a wildfire event in a wet $E$. obliqua forest than after a CBS operation due to the greater presence of biological legacies, i.e., organically produced patterns and structures (as mentioned above) that survive the disturbance.

The value of a small spatial scale study is that it provides baseline knowledge of an area in sufficient detail that can then be extrapolated to a larger landscape level. The accumulated knowledge from multiple small spatial studies has a use in assessing effects of habitat fragmentation on biodiversity. Furthermore, heterogeneity at the small-scale level may also indicate heterogeneity at a landscape level. Data analysis programs exist (see Holland et al. 2004) that can extrapolate small scale data into larger landscape level results leading to reduced costs (time, labour and travel) associated with intensive large-scale studies. Additionally, small spatial scale studies can gauge the success of specific habitat refugia, such as nature reserves and wildlife connectivity corridors.

The objectives of this study were to investigate the diversity of wood-inhabiting fungi in a 43-year-old regenerating $E$. obliqua forest by documenting the species numbers and species assemblages present, and to compare the effects of clearfell, burn and sow silviculture with the effects of wildfire on the wood-inhabiting fungi present in four plots. This is done within the context of an experimental design where two paired plots (one subjected to CBS and one which experienced wildfire) were examined at each of two localities in 'Tasmania's southern forests. The CBS regenerating stands are even-aged stands of 43 years, whereas the wildfire stands are of mixed age due to the erratic nature of wildfire in the tall, wet, E. obliqua forests of southern Tasmania (Alcorn et al. 2001, Turner et al. 2009). The opportunity also presented itself to investigate if a shortterm study at this small spatial scale can provide data that can be incorporated into forestry management protocols. Specific questions relating to the above aims included whether there was a relationship between the macrofungal species diversity and the dead wood characteristics such as its species, decay class, diameter class, and whether the wood was fallen, suspended or upright. Also examined were whether the wood-inhabiting fungal assemblages depended upon vegetation type, soil $\mathrm{pH}$, canopy and ground cover, and whether the diversity of the macrofungal assemblages on wood differed between the two disturbance treatments. We speculate about whether the findings from this study might influence the current use of CBS or alternatively, aggregated retention (ARN), a silvicultural procedure, in which "islands" of unharvested trees are retained for one or two rotations, under consideration for use in sustainable forestry in Tasmania. We further speculate whether there are any implications from this study on impacts on diversity of wood-inhabiting macrofungal assemblages from the intended harvesting of dead wood in Tasmania as a biofuel for power generation. We ask whether this short-term, small spatial scale study could reflect any results from similar, more intensive studies in E. obliqua forests of southern Tasmania, such as the one by Gates (2009).

\section{MATERIALS AND METHODS}

\section{Study area, plot location and establishment}

Four plots in native, tall, wet Eucalyptus obliqua forest in southern Tasmania, west of Geeveston were examined (fig. 1). All four plots, two from wildfire and two from a CBS forestry regeneration procedure, were part of larger forest tracts that had experienced disturbance in the years 1966/67. Two of these plots were directly opposite each other on either side of Hartz Rd, with the northern plot having been subjected to CBS regeneration and the southern plot having experienced wildfire. At Edwards Rd, the two plots were side-by-side on the north side of the road, the most easterly plot having been disturbed by wildfire in 1966/67, with the westernmost plot being a CBS plot. The four plots were used previously, along with other plots, as part of a study by Browning et al. (2010) on cryptogamic succession (mosses, liverworts and ferns) in these same regenerating wet eucalypt forests.

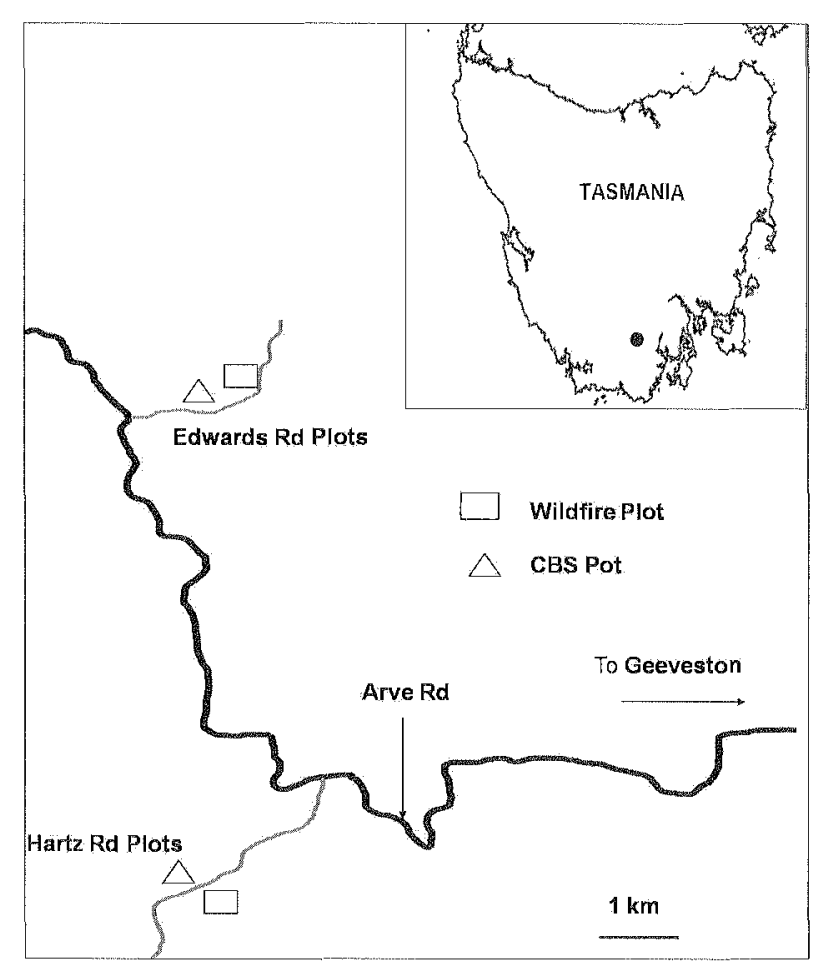

FIG. 1 - Map of site in southern Tasmania showing plot locations. 
At each site (Hartz Rd and Edwards Rd), a $40 \times 40 \mathrm{~m}$ plot was measured and marked out using twine, and each plot was divided into four $20 \times 20 \mathrm{~m}$ quadrants.

\section{Site characterisation}

The slope, canopy cover, soil $\mathrm{pH}$, ground cover and dominant vascular plants of each plot in the study were measured. The location of the chosen central point of each plot was determined with a handheld Garmin E-Trex ${ }^{\circledR}$. The angle of slope was measured with a handheld Suunto ${ }^{\text {(1) }}$ clinometer at three random positions within each quadrant. The 12 readings were then averaged to give an average slope for each site. The canopy covered by the dominant vegetation was measured at three random positions within each quadrant using a Forestry Suppliers Inc. Spherical Crown Densiometer ${ }^{\text {(i). At }}$ each position four observations (each facing north, south, east and west) were recorded. The averages of these readings were calculated to give a percentage canopy cover for each quadrant. Soil was sampled in three randomly generated locations within each quadrant. Samples were taken at a depth of 10-20 cm using a hand trowel, placed in a plastic bag and taken back to the laboratory for analysis using a Manutec ${ }^{\text {(1) }}$ soil $\mathrm{pH}$ test kit to obtain an average soil $\mathrm{pH}$ for each quadrant. The percentage of ground covered by bare ground, litter, rock, bryophytes and dead wood separately was recorded at three random locations in each plot. For each component of ground cover, the percentage of cover was recorded as an absolute value and converted using a modified Braun-Blanquet cover class for analysing ground cover abundance data, as follows: $0=$ absent $1=1-25 \% ; 2=26-50 \% ; 3=51-75 \% ; 4=76-100 \%$. The living stems of all vascular plants of height $\geq 1.5 \mathrm{~m}$ within each quadrant of each plot were identified to species using Eucaflip (Wiltshire \& Potts 2007) and Treeflip (Wiltshire \& Jordan 2009). The diameter at breast height (DBH) of each stem was measured using a diameter tape measure. From these measurements, the basal area of each tree and the percentages of basal area at the plot level occupied by each tree species were subsequently calculated.

\section{Macrofungal survey method}

Each quadrant was visited fortnightly from 6 May-15 July 2010 , a total of six visits. This was determined to be the ideal time for collection, covering the optimal fruiting season for the majority of Tasmanian macrofungi (Gates \& Ratkowsky 2009), where a macrofungus is defined as a fungus that may be seen with the unaided eye. In the first five visits a $20 \mathrm{~m}$ transect was followed in each of the four quadrants in a predetermined location and order. During the last visit (15 July 2010), each quadrant was surveyed randomly for 15 minutes. At each visit, the species binomial or "tag" name of each macrofungus observed on fallen wood or a stag within $1 \mathrm{~m}$ on each side of the transect was recorded. Resupinate species, if not readily identifiable, were ignored due to time considerations and lack of taxonomic expertise. For each species, only its presence (not its abundance) was recorded, and its substrate was classified according to its diameter class, decay class and plant species. Voucher specimens of known species, to be deposited in the Tasmanian Herbarium (HO), were collected at the first encounter and dried in an air dryer for 24-48 hours in the laboratory. All species new to the authors were macro-and microscopically described. Valid names were obtained from the website Index Fungorum (http://www. indexfungorum.org/names/names.asp, viewed November 2010). For each macrofungal species, the diameter class, level of decay and species of substrate was also recorded. For wood size, three diameter classes (small, $\mathrm{D} \leq 10 \mathrm{~cm}$; medium, $10<\mathrm{D}<40 \mathrm{~cm}$; large, $\mathrm{D} \geq 40 \mathrm{~cm}$ ) were used. The level of decay of each substrate was also classified into three classes- low, medium and high - based on appearance and structural stability using certain defined characteristics (table 1).

\section{Statistical analysis}

From the presence/absence data from the six fortnightly visits to each of the four quadrants of each of the four plots, species lichness was calculated as the number of distinct macrofungal species observed. Randomised species accumulation curves were prepared to visualise the rate at which new species of wood-inhabiting macrofungi were observed over the study period, using the Mao-Tau estimator available in the package EstimateS (Colwell 2005). For species assemblages, nonmetric multidimensional scaling (nMDS) and one of the routines (DISTLM) in the suite of programs for multivariate ecological data developed by M.J. Anderson and available as an add-on (PERMANOVA+) to PRIMER v6 (Clarke \& Gorley 2006, Anderson et al. 2008) were used as inferential methods. DISTLM (and its associated plotting routine dbRDA) can be used on the macrofungal data recorded during the fortnightly visits because their use does not require any a priori distributional assumptions to be satisfied. Starting with the basic data tables of the presence or absence of each macrofungal species recorded on dead wood, similarity (resemblance) was defined using the Bray-Curtis measure (Bray \& Curtis 1957). Significance levels were provided by permutation trials, using 9999 random permutations of the observed data set. The major question that was tested was

\section{TABLE 1}

Description of the characteristics assigned to each wood decay class

\begin{tabular}{ll}
\hline Decay Class & Characteristics \\
\hline Low & Some to most of the bark is present; branches may retain twigs; wood is solid. \\
Medium & Bark is absent; log can be broken with some applied force, but is still structurally sound. \\
High & $\begin{array}{l}\text { Log cannot support own weight; structure is soft and crumbly and can be broken or crushed } \\
\text { easily by kicking; bryophytes, ferns and invading roots may be present. }\end{array}$
\end{tabular}


whether there was an association between the macrofungal species lists obtained from each of the four quadrants of cach plot and the living vascular plant species present in those quadrants. DISTLM uses two data matrices, one containing the Bray-Curtis resemblances among the macrofungal species lists in each of the 16 quadrants and the other containing the abundances of the vascular plant species present in those same quadrants. Conditional upon a significant $\mathrm{P}$-value being obtained, DISTLM then establishes which of the vascular species best explained the differences among the macrofungal species assemblages at the quadrant level, and the graph available from dbRDA was used to visualise the differences.

\section{RESULTS}

\section{Slope, canopy cover and soil $\mathrm{pH}$}

Table 2 summarises the mean slope, canopy cover and soil $\mathrm{pH}$ for the four plots. The slope of both plots at Edwards $\mathrm{Rd}$ was greater on average than at the Hartz Rd plots. The percentage canopy cover at all four plots was high with little difference between them, and the same was true of soil $\mathrm{pH}$, the soils all being slightly acidic, with the difference in plot $\mathrm{pH}$ means being at most 0.5 of a $\mathrm{pH}$ unit.

TABLE 2

Site characteristics for each plot $^{1}$

\begin{tabular}{lccc}
\hline Site & Slope $\left(^{\circ}\right)$ & $\begin{array}{c}\% \text { Canopy } \\
\text { cover }\end{array}$ & Soil pH \\
\hline Hartz Rd CBS & $21(19-22)$ & $87(81-90)$ & $5(4-6)$ \\
Hartz Rd Wildfire & $20(14-33)$ & $93(92-94)$ & $5(5-5)$ \\
Edwards Rd CBS & $35(27-50)$ & $92(91-94)$ & $5.25(5-6)$ \\
Edwards Rd Wildfire & $30(25-33)$ & $93(93-93)$ & $4.75(4-5)$ \\
\hline
\end{tabular}

${ }^{1}$ Entries are plot means, with the ranges from the four quadrants given in parentheses.

\section{Ground cover}

There was little difference between the plots with regard to ground cover, with all plots having a large average cover of litter present (fig. 2). Both wildfire plots contained a slightly greater cover of dead wood on average than the CBS plots (fig. 2).

\section{Vascular plant species composition}

The total number of stems recorded over all plots was 2652 (table 3). The Edwards Rd CBS plot contained the most living stems of all plots with 1024 and the Hartz Rd CBS plot contained the least with 195 stems. The difference is mostly due to the large number of Pomaderris apetala Labill. at ECBS plus a smaller difference in Olearia argophylla (Labill.) F. Muell. ex Benth., which more than balanced the decreased numbers of Nothofagus cunninghamii (Hook.) Oerst. and of Acacia dealbata Link at that site. Eucalyptus obliqua was the dominant canopy species in all plots, with $>50 \%$ basal area at each plot, although it was never the most numerous in terms of number of stems. Both Edwards Rd plots contained large numbers of $P$. apetala, which accounted for $>40 \%$ of the basal area of those plots, to the detriment of rainforest species such as $N$. cunninghamii, Atherosperma moschatum Labill. and Eucryphia lucida (Labill.) Baill. This was in contrast to the Hartz Rd plots, which contained little or no P. apetala, but more rainforest species plus $A$. dealbata.

\section{Macrofungal species richness}

The six fortnightly visits yielded 90 species from 619 records on dead wood in the four plots surveyed. Of these, the 77 species believed to prefer wood as its substrate are listed in table 4 and were used in the subsequent statistical analyses. Table 4 also gives the number of records of each species, their wood decay class and diameter class, the plot in which they were recorded, the wood substrate species, and whether the wood was fallen, suspended, or a stag.

TABLE 3

Species of higher vascular plants with living stems of height $\geq 1.5 \mathrm{~m}$, total number of stems and percentage basal area per plot (in parentheses), and total basal area of stems, in each of the four plots

\begin{tabular}{lllll}
\hline & \multicolumn{4}{c}{ Plot identification } \\
Vascular plant species & \multicolumn{1}{c}{ HCBS } & \multicolumn{1}{c}{ HWF } & \multicolumn{1}{c}{ ECBS } & EWF \\
\hline Acacia dealbata & $26(21.8)$ & $23(11.1)$ & $2(0.3)$ & $5(2.6)$ \\
Atherosperma moschatum & $6(0.3)$ & $7(0.3)$ & $2(0.0)$ & $0(0.0)$ \\
Eucalyptus obliqua & $41(66.7)$ & $69(72.0)$ & $50(53.2)$ & $57(55.2)$ \\
Eucryphia lucida & $0(0)$ & $45(1.7)$ & $1(0.7)$ & $0(0.0)$ \\
Nothofagus cunninghamii & $71(5.5)$ & $638(14.6)$ & $0(0.0)$ & $0(0.0)$ \\
Olearia argophylla & $23(3.9)$ & $4(0.1)$ & $154(5.7)$ & $8(0.3)$ \\
Phyllocladus aspleniifolius & $5(0.1)$ & $3(0.0)$ & $6(0.0)$ & $0(0.0)$ \\
Pittosporum bicolor & $1(0.1)$ & $2(0.1)$ & $0(0.0)$ & $0(0.0)$ \\
Pomaderris apetala & $22(1.6)$ & $1(0.0)$ & $809(40.1)$ & $571(41.9)$ \\
Total stems (\% BA) & $195(100)$ & $792(100)$ & $1024(100)$ & $641(100)$ \\
Stems total basal area (m²/ha) & 68.7 & 69.6 & 62.6 & 53.8 \\
\hline
\end{tabular}

HCBS=Hartz Rd CBS; HWF=Hartz Rd Wildfire; ECBS=Edwards Rd CBS; EWF=Edwards Rd Wildfire. 


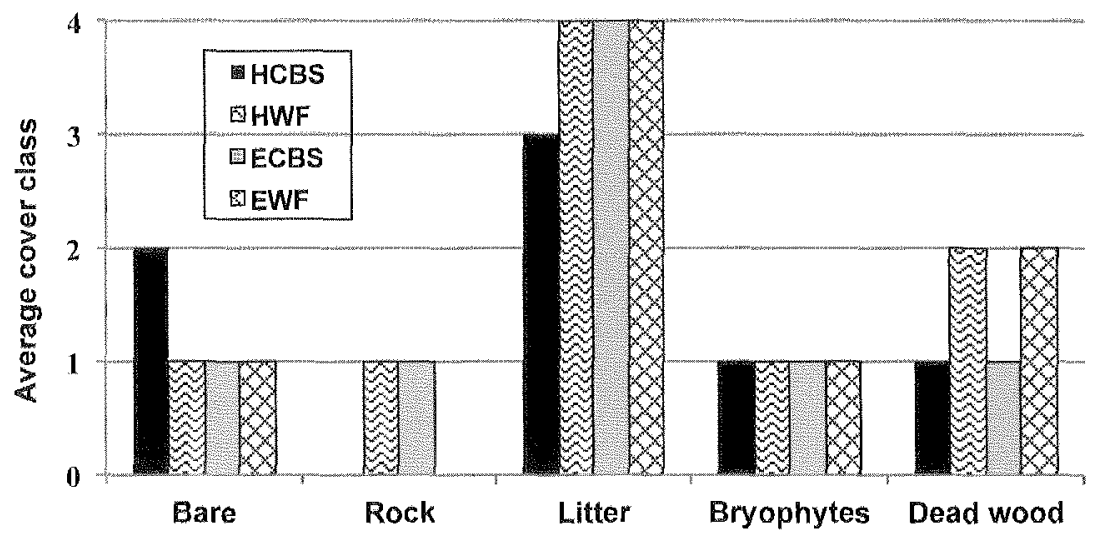

FIG. 2 - Average cover classes (modified Braun-Blanquet scores) for observed ground cover on each plot (HCBS=Hartz Rd $C B S ; H W F=$ Hartz Rd Wildfire; ECBS=Edwards Rd CBS; EWF=Edwards Rd Wildfire).

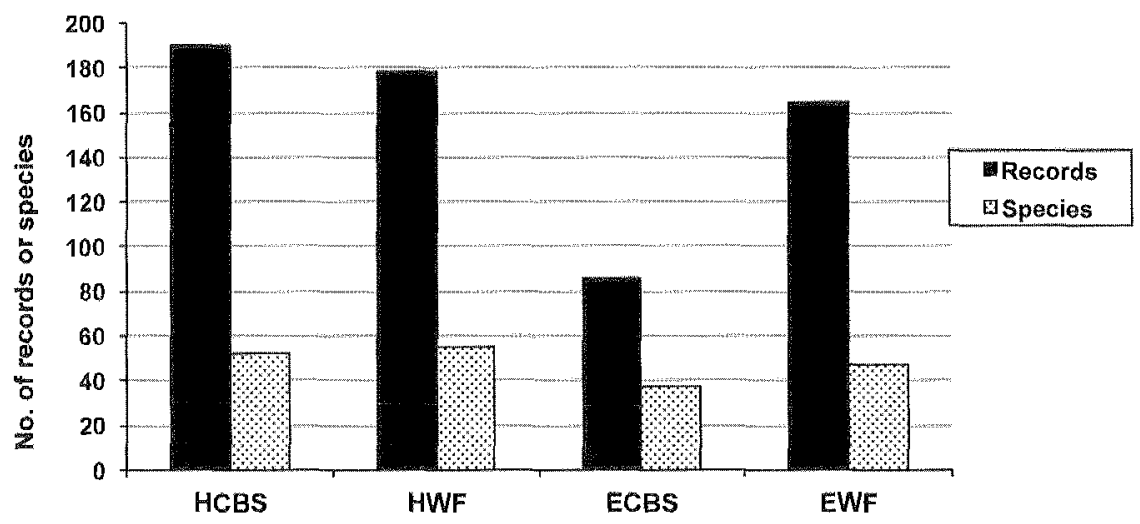

FIG. 3 - Number of records and number of species of macrofungi in each plot from six visits (HCBS=Hartz Rd CBS; $H W F=$ Hartz Rd Wildfire; $E C B S=E d w a r d s$ Rd CBS; EWF=Edwards Rd Wildfire).

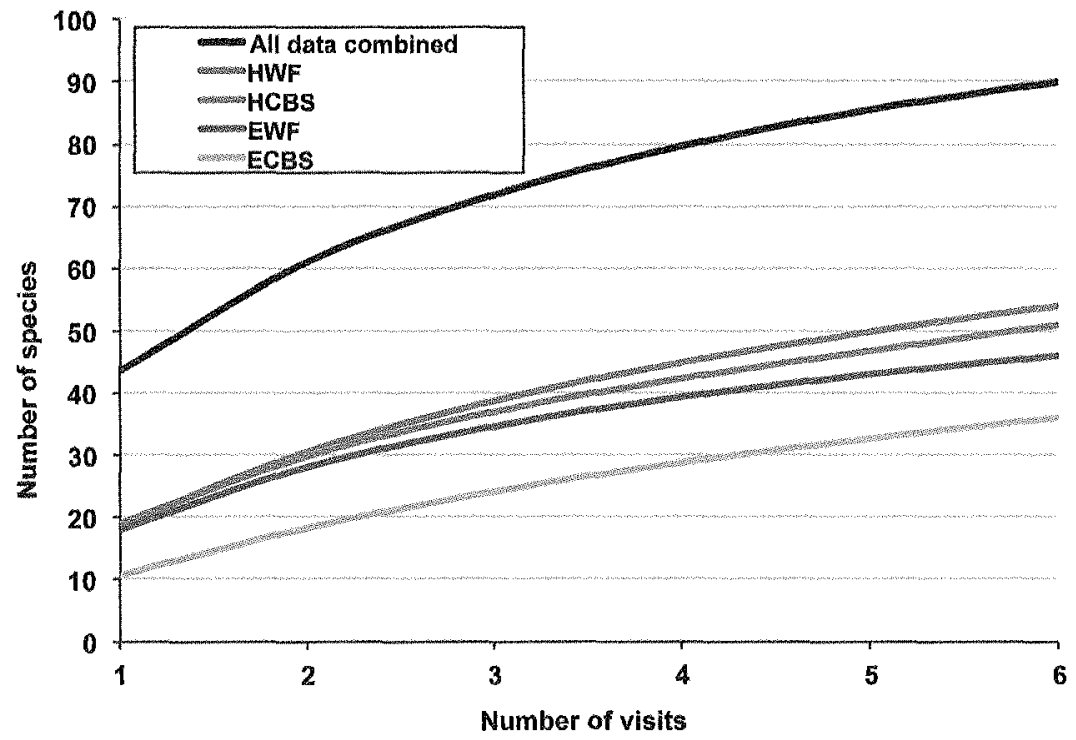

FIG. 4-Randomised macrofungal species accumulation curves for each plot and for all plots combined (HWF=Hartz Rd Wildfire; HCBS=Hartz Rd CBS; EWF=Edwards Rd Wildfire; ECBS $=$ Edwards Rd CBS). 
TABLE 4

Compilation of the 77 wood-preferring macrofungal species collected during the survey. The records are classified by their wood decay class and diameter class, the plot in which they were recorded, the wood substrate, and whether the substrate was suspended, not suspended, or a stag

Wood substrate ${ }^{5}$ Wood suspended? Antauroderma rude (Berk.) Torrend

records $^{1}$ L

lot identification ${ }^{4}$

Armillaria novae-zelandiae (G. Stev.) Herink

Ascocoryne sarcoides (Jacq.) J.W. Groves \& D.E. Wilson

Ascomycete "white brusing orange"

Australoporus tasmanicus (Berk.) P.K. Buchanan \& Ryvarden

Biscogniauxia sp.

Bisporella "green-yellow"

Bisporella citrina (Batseh) Korf \& S.E. Carp.

Byssomerulius corium (Pers.) Parmasto $\geq$

Callistosporium "Maroon on wood"

Calocera "spathulate"

Calocera guepinioides Berk.

Chlorociboria aeruginascens (Nyl.) Kanouse

Clavicorona piperata (Kauffman) Leathers \& A.H. Sm.

Clitocybula "Maria on wood"

Collybia eucalyptorum Cleland

Crepidotus "orange"

Crepidotus nephrodes (Berk. \& M.A. Curtis) Sacc. Daldinia grandis Child

Exidia sp.

Galerina patagonica Singer

Ganoderma australe (Fr) Pat.

Gloeoporus taxicola (Pers.) Gilb. \& Ryvarden

Gymnopilus allantopus (Berk.) Pegler

Gymnopilus ferruginosus B.J. Rees

Gymnopilus tyallus Grgur.

Hericium coralloides (Scop.) Pers.

Heterotextus peziziformis (Berk.) Lloyd

Hohenbuehelia sp.

Hypholoma brunneum (Massee) D.A. Reid

Hypholoma fasciculare (Huds. : Fr.) P. Kumm.

Hypocrea megalosulphurea Yoshim. Doi

Hypoxylon aff. placentiforme Berk. \& M.A. Curtis

Hypoxylon crocopeplum Berk. \& M.A. Curtis

Junghuhnia rhinocephala (Berk.) Ryvarden

Lanzia lanaripes (Dennis) Spooner

Lentinellus pulvinulus (Berk.) Pegler

Marasmiellus affixus (Berk.) Singer

Melanotus hepatochrous (Berk.) Singer

Mollisia cinerea (Batsch) P. Karst

(1)


Mycena interrupta (Berk.) Sacc.

Mycena kuurkacea Grgur.

Mycena maldea Grgur.

Mycena mulawaestris Grgur

Mycena nargan Grgur.

Mycena subgalericulata Cleland

Panellus stipticus (Bull.) P. Karst.

Pholiota multicingulata E. Horak

Pluteus atromarginatus (Konrad) Kühner

Polyporus gayamis Lév.

Polyporus melanopus (Sw. : Fr.) Fr.

Postia dissecta (Lév.) Rajchenb.

Postia lactea (Fr.) P. Karst

Postia pelliculosa (Berk.) Rajchenb.

Postia punctata Rajchenb. \& P.K. Buchanan

Postia subcaesia (A. David) Jülich.

Postia venata (Rajchenb. \& J.E. Wright) Rajchenb.

Psathyrella "pale brown gills"

Psathyrella echinata (Cleland) Grgur.

Psathyrella sp.

Pseudohydnum gelatinosum (Scop.) P. Karst.

Simocybe phlebophora E. Horak

Skelefocutis nivea (Jungh.) Jean Keller

Stecherinum ochraceum (Pers.) Gray

Stereum hirsutum (Willd.) Pers.

Steretm illudens Berk.

Stereum ostrea (Blume \& T. Nees) Fr.

Stereum rugosum Pers.

Tremella fimbriata Pers.

Tricholomopsis rutilans (Schaeff.) Singe

Tubaria rufofulva (Cleland) D.A. Reid \& E. Horak

Vibrissea dura G.W. Beaton \& Weste

Xylaria castorea Berk.

\begin{tabular}{|c|c|c|c|c|c|c|c|c|c|c|c|c|c|c|c|c|c|c|c|}
\hline 3 & 0 & 3 & 0 & 0 & 0 & 3 & 0 & 1 & 0 & 2 & 0 & 0 & 3 & 0 & 0 & 0 & 3 & 0 & 0 \\
\hline 2 & 1 & 1 & 0 & 2 & 0 & 0 & 0 & 2 & 0 & 0 & 0 & 0 & 0 & 0 & 0 & 2 & 1 & 0 & 1 \\
\hline 3 & 1 & 1 & 1 & 0 & 3 & 0 & 2 & 0 & 0 & 1 & 0 & 0 & 3 & 0 & 0 & 0 & 1 & 0 & 2 \\
\hline 17 & 3 & 12 & 2 & 2 & 10 & 5 & 5 & 1 & 7 & 4 & 0 & 0 & 15 & 0 & 0 & 2 & 8 & 0 & 9 \\
\hline 41 & 7 & 25 & 9 & 14 & 25 & 2 & 7 & 5 & 16 & 13 & 0 & 0 & 35 & 0 & 0 & 6 & 9 & 1 & 31 \\
\hline 21 & 5 & 14 & 2 & 8 & 10 & 3 & 9 & 3 & 7 & 2 & 0 & 0 & 15 & 0 & 2 & 4 & 11 & 0 & 10 \\
\hline 7 & 0 & 6 & 1 & 0 & 4 & 3 & 0 & 0 & 1 & 6 & 1 & 0 & 6 & 0 & 0 & 0 & 4 & 0 & 3 \\
\hline 23 & 3 & 14 & 6 & 4 & 16 & 3 & 0 & 2 & 12 & 9 & 2 & 0 & 19 & 0 & 0 & 2 & 16 & 0 & 7 \\
\hline 2 & 0 & 2 & 0 & 0 & 2 & 0 & 0 & 0 & 0 & 2 & 0 & 0 & 2 & 0 & 0 & 0 & 1 & 0 & 1 \\
\hline 19 & 1 & 17 & 1 & 2 & 3 & 14 & 3 & 5 & 6 & 5 & 0 & 0 & 19 & 0 & 0 & 0 & 16 & 0 & 3 \\
\hline 1 & 0 & 1 & 0 & 0 & 1 & 0 & 0 & 0 & 1 & 0 & 0 & 0 & 1 & 0 & 0 & 0 & 0 & 0 & 1 \\
\hline 12 & 2 & 7 & 3 & 4 & 7 & 1 & 1 & 8 & 3 & 0 & 1 & 0 & 5 & 0 & 0 & 6 & 7 & 1 & 4 \\
\hline 1 & 0 & 1 & 0 & 0 & 1 & 0 & 0 & 0 & 0 & 1 & 0 & 0 & 1 & 0 & 0 & 0 & 0 & 0 & 1 \\
\hline 3 & 0 & 2 & 1 & 2 & 1 & 0 & 2 & 1 & 0 & 0 & 0 & 0 & 0 & 0 & 0 & 3 & 0 & 0 & 3 \\
\hline 4 & 2 & 2 & 0 & 0 & 4 & 0 & 0 & 4 & 0 & 0 & 0 & 0 & 0 & 0 & 0 & 4 & 2 & 0 & 2 \\
\hline 8 & 0 & 7 & 1 & 0 & 8 & 0 & 1 & 0 & 5 & 2 & 0 & 0 & 8 & 0 & 0 & 0 & 4 & 1 & 3 \\
\hline 1 & 0 & 0 & 1 & 1 & 0 & 0 & 0 & 1 & 0 & 0 & 0 & 0 & 0 & 0 & 0 & 1 & 0 & 0 & 1 \\
\hline 6 & 0 & 5 & 1 & 2 & 1 & 3 & 1 & 2 & 0 & 3 & 1 & 0 & 5 & 0 & 0 & 0 & 4 & 1 & 1 \\
\hline 10 & 0 & 8 & 2 & 0 & 1 & 9 & 3 & 3 & 0 & 4 & 0 & 0 & 10 & 0 & 0 & 0 & 8 & 2 & 0 \\
\hline 2 & 1 & 0 & 1 & 2 & 0 & 0 & 1 & 1 & 0 & 0 & 0 & 0 & 0 & 0 & 0 & 2 & 1 & 0 & 1 \\
\hline 2 & 0 & 2 & 0 & 0 & 1 & 1 & 0 & 0 & 1 & 1 & 0 & 0 & 2 & 0 & 0 & 0 & 2 & 0 & 0 \\
\hline 1 & 0 & 0 & 1 & 1 & 0 & 0 & 0 & 0 & 1 & 0 & 0 & 0 & 1 & 0 & 0 & 0 & 1 & 0 & 0 \\
\hline 2 & 0 & 2 & 0 & 0 & 2 & 0 & 1 & 0 & 0 & 1 & 0 & 0 & 2 & 0 & 0 & 0 & 1 & 0 & 1 \\
\hline 3 & 1 & 1 & 1 & 1 & 2 & 0 & 1 & 1 & 0 & 1 & 0 & 0 & 2 & 1 & 0 & 0 & 2 & 0 & 1 \\
\hline 2 & 0 & 1 & 1 & 0 & 2 & 0 & 0 & 0 & 1 & 1 & 0 & 0 & 2 & 0 & 0 & 0 & 1 & 1 & 0 \\
\hline 2 & 0 & 1 & 1 & 2 & 0 & 0 & 0 & 2 & 0 & 0 & 0 & 0 & 0 & 0 & 0 & 2 & 2 & 0 & 0 \\
\hline 4 & 0 & 4 & 0 & 2 & 2 & 0 & 1 & 0 & 1 & 2 & 1 & 0 & I & 0 & 0 & 2 & 1 & 0 & 3 \\
\hline 3 & 1 & 2 & 0 & 2 & 1 & 0 & 0 & 3 & 0 & 0 & 0 & 0 & 0 & 0 & 0 & 3 & 3 & 0 & 0 \\
\hline 1 & 0 & 1 & 0 & 0 & 1 & 0 & 0 & 1 & 0 & 0 & 0 & 0 & 0 & 0 & 0 & 1 & 1 & 0 & 0 \\
\hline 4 & 3 & 1 & 0 & 3 & 1 & 0 & 1 & 0 & 2 & 1 & 0 & 0 & 4 & 0 & 0 & 0 & 1 & 0 & 3 \\
\hline 2 & 1 & 1 & 0 & 1 & 1 & 0 & 1 & 1 & 0 & 0 & 0 & 0 & 0 & 0 & 0 & 2 & 1 & 0 & 1 \\
\hline 25 & 17 & 8 & 0 & 13 & 12 & 0 & 0 & 8 & 8 & 9 & 0 & 0 & 24 & 0 & 0 & 1 & 13 & 0 & 12 \\
\hline 1 & 1 & 0 & 0 & 1 & 0 & 0 & 0 & 0 & 1 & 0 & 0 & 0 & 1 & 0 & 0 & 0 & 1 & 0 & 0 \\
\hline 2 & 2 & 0 & 0 & 0 & 0 & 2 & 0 & 2 & 0 & 0 & 0 & 0 & 2 & 0 & 0 & 0 & 2 & 0 & 0 \\
\hline 1 & 0 & 1 & 0 & 0 & 1 & 0 & 0 & 0 & 0 & 1 & 0 & 0 & 1 & 0 & 0 & 0 & 0 & 0 & 1 \\
\hline 18 & 1 & 15 & 2 & 0 & 12 & 6 & 2 & 0 & 11 & 5 & 0 & 0 & 18 & 0 & 0 & 0 & 17 & 0 & 1 \\
\hline 1 & 0 & 0 & 1 & 1 & 0 & 0 & 0 & 0 & 1 & 0 & 0 & 0 & 1 & 0 & 0 & 0 & 0 & 0 & 1 \\
\hline als $^{(7)} \quad 619$ & 142 & 367 & 110 & 204 & 278 & 137 & 86 & 165 & 190 & 178 & 22 & 2 & 472 & 3 & 2 & 118 & 349 & 17 & 253 \\
\hline
\end{tabular}

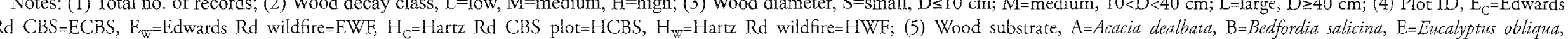

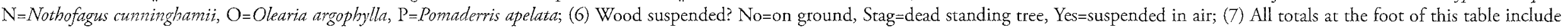
the records for 13 species considered to prefer litter or soil rather than wood, but which were found in association with wood in this study. 
The two Hartz Rd plots had a similar number of macrofungal records and species, with the CBS and wildfire plots having 54 and 51 species, respectively (fig. 3). At Edwards Rd the diversity was lower in both plots, especially the number of species in the CBS plot (36 compared to 46 in the wildfire plot). In the randomised species accumulation curves (fig. 4), the distances between the curve for the data from all plots combined and the curves for the individual plots suggest that the commonality among the species in the different plots is not high, each individual plot containing some unique macrofungal species, the identities of which may be determined from table 4 .

\section{Macrofungal species assemblages}

The species assemblages in the four plots were different, as shown by the first two axes of a 3-d nMDS ordination (fig. 5 , stress $=0.09$ ). The figure clearly separates the assemblages in the Hartz Rd plots from those in Edwards Rd, but within Hartz Rd there is a fair amount of overlap between the macrofungi in the CBS and wildfire plots. This overlap is not resolved on the third axis (not shown). The results of DISTLM regression modelling using the first two dbRDA axis (fig. 6), reinforces the message of the nMDS ordination, with the two plots at Hartz Rd clearly separated from the Edwards Rd plots and from each other, but with the two Edwards Rd plots overlapping and not separated on the third dbRDA axis (not shown). The important predictor variables are summarised in table 5, which shows that the number of live $P$ apetala stems was the main indicator of differences among the plots, with the number of live $O$. argophylla stems being the second most important. The physical properties of the plot quadrants, viz. the soil $\mathrm{pH}$, slope, canopy cover and the components of the ground cover, did not contribute significantly to explaining differences in the macrofungi found in the experimental units.

\section{DISCUSSION}

\section{Macrofungal species richness}

The total of 77 wood-preferring species (table 4) is high compared to the diversity found at other locations in Australia (Hilton et al. 1989, 40 spp.; Burns \& Conran 1997, 13 spp.; McMullan-Fisher et al. 2002, 35 spp.; Robinson et al. 2003, 63 spp.; Robinson \& Tunsell 2007, 68 spp.). However, those studies were in Western Australia, South Australia or Victoria, in different forest types and where the macrofungal fruiting season is shorter in their warmer, drier climate compared

TABLE 5

DISTLM modelling using a stepwise procedure, showing the significant explanatory variables for the macrofungal assemblages

\begin{tabular}{lcc}
\hline $\begin{array}{l}\text { Explanatory variables } \\
\text { entered }\end{array}$ & P-value & $\begin{array}{c}\text { Cumulative } \mathrm{R}^{2} \\
\text { explained }\end{array}$ \\
\hline $\begin{array}{l}\text { Pomaderris apetala } \\
\text { Olearia argophylla }\end{array}$ & 0.0006 & 0.159 \\
Phyllocladus asplenifolius & 0.0420 & 0.257 \\
\hline
\end{tabular}

with Tasmania. Gates et al. (2011c), in a study conducted over a period of 14 months of fortnightly visits to a larger plot area $(0.25$ ha compared with $0.16 \mathrm{ha})$ not far from that of the present study, identified 308 species that can be classified as wood-preferring macrofungi. Of those 308 species, 69 were also found in this study. The remaining 239 species included many resupinate species, a group that due to time limitations could not be examined in great detail. In addition, Hopkins et al. (2011) found 91 putative operational taxonomic units (OTUs) from 18 living E. obliqua trees in an area close to the present study. However, that study was based on isolating fungi from the wood and identifying from cultures and from molecular techniques. Most of the OTUs could not be matched with a macrofungal fruit body and some may never form a fruit body during their life cycle. This further supports the notion that fungal diversity in $E$. obliqua forests is very high.

The number of species present in each of the quadrants, used as a measure of species richness, did not lead to a significant difference due to treatment (CBS vs. wildfire) in this study, as the low species numbers in ECBS compared with EWF at Edwards Rd was not matched by the results at Hartz Rd (see fig. 3). Similarly, Browning et al. (2010) found that species richness of mosses, liverworts and ferns on coarse woody debris was not significantly different in CBS and post-wildfire 43-year-old plots in this same forest.

\section{Macrofungal species richness - substrate species}

A noteworthy result from the present survey is the fact that $95 \%$ of the 619 macrofungal records occurred on only two substrate species, viz. Eucalyptus obliqua (76\%) and Pomaderris apetala (19\%). Only three records $(0.5 \%)$ occurred on Nothofagus cunninghamii, a sharp contrast to South America and New Zealand, where Nothofagus forests are the supporters of many native macrofungal species (for NewZealand, see McKenzie et al. 2000). In Tasmania, woodinhabiting polypore species found on Nothofagus in South America (Rajchenberg 2006) prefer eucalypt wood rather than Nothofagus (Gates etal. 2011. ). Evidence from previous surveys suggest that eucalypt-dominated forests are also rich in ectomycorrhizal macrofungal species in soil (Gates $e t a l$. $2011 \mathrm{a}$ ) and in litter (Gates et al. 2011b). Further evidence comes from Western Australia (Robinson \& Tunsell 2007), where there are no extant Nothofagus species, but which did occur in the past as a legacy from Gondwanaland (Bougher et al. 1994, Carpenter \& Pole 1995). The modern Western Australian forests that are rich in macrofungi are dominated either by Eucalyptus diversicolor F.Muell. or E. marginata Sm., which is evidence that, in Australia, eucalypts may be the major vascular plant host of macrofungi. In the present study, Pomaderris was an important secondary host to Eucalyptus, with 35 species found on $P$ apetala, of which 13 were found only on this species (table 4). This reinforces the finding from Gates et al. (2011c), where fallen and suspended $P$ apetala occurred abundantly in two of the four plots surveyed and supported 85 macrofungal species of which 33 were only on that substrate. Fallen $P$ apetala produces a lot of small to medium diameter wood in the low or medium decay class, which can support what Rayner \& Boddy (1988) refer to as "latent invader" fungi, an example of which is Hypoxylon aff. placentiforme Berk. \& M.A. Curtis, found frequently in this study. Also, as P. apetala has a very smooth bark, it may 


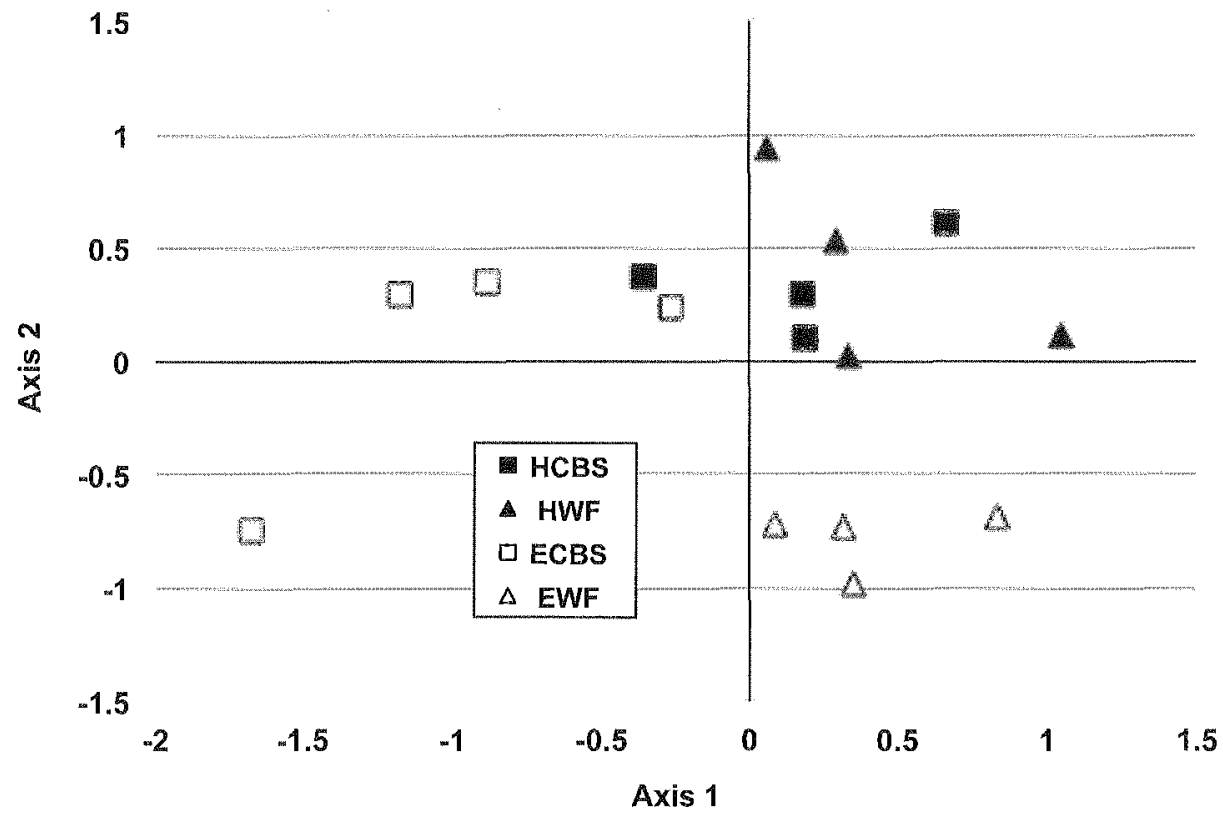

FIG. 5 - The first two axes of a three-dimensional non-metric multidimensional scaling ordination applied to the Bray-Curtis resemblance matrix obtained from the macrofungal species assemblages observed during the six visits (stress $=0.09)(H C B S=H a r t z$ Rd CBS; HWF=Hartz Rd Wildfire; ECBS=Edwards Rd CBS; EWF=Edwards Rd Wildfire).

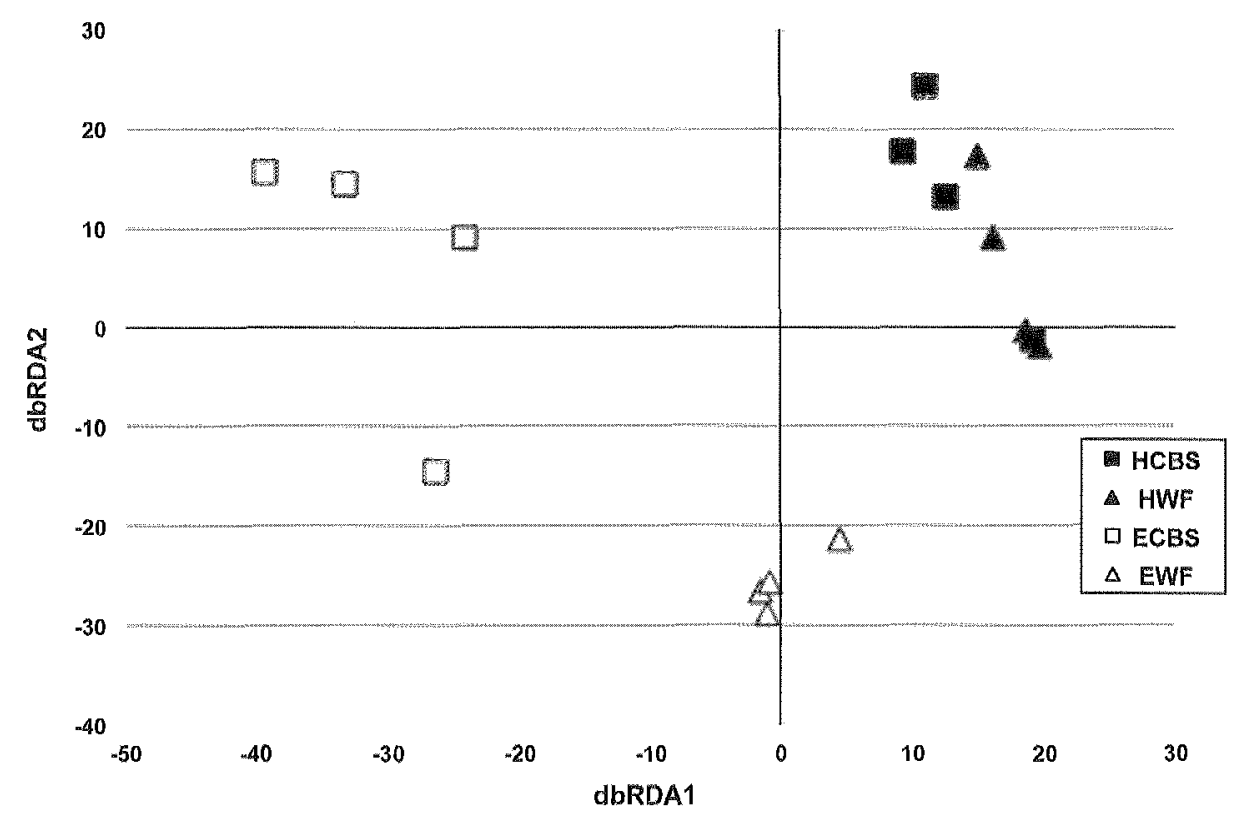

FIG. 6 - dbRDA graph of best DISTLM model, the points representing the macrofungal species assemblages pooled over six visits in four quadrants of each of the four plots (HCBS=Hartz Rd CBS; HWF=Hartz Rd Wildfire; ECBS=Edwards Rd CBS; $E W F=$ Edwards Rd Wildfire). 
present a more favourable surface for spore colonisation to some species of fungi (see Renvall 1995).

\section{Macrofungal species assemblages - influence of site variables}

The vascular plant community was shown to have a significant effect on the macrofungal assemblages found (table 5, figs 5 \& 6). The important influence of the vascular plant communities was also shown for the southern wet $E$. obliqua forests of Tasmania by Packham et al. (2002), who found a distinct difference between the macrofungal assemblages in mature (generally longunburnt) and regrowth (recentlyburnt) forests.

\section{Some further observations}

Table 4 includes several species usually associated with old forests in Tasmania. These species occur either on large diameter wood, highly decayed wood, or are host specific. They are not confined to any one plot in this study but are found on biological legacies from a predisturbed stand irrespective of type of disturbance. For example, Hericium coralloides (see table 4 for naming authorities of the fungi) was found on a well-decayed stag of $N$. cunninghamii in the Hartz CBS plot, and Australoporus tasmanicus was found on a large diameter log in a high decay class in the Hartz wildfire plot. The common brown heart-rot fungus Postia punctata was present in all plots (mostly on large diameter wood in a medium decay class) except for Hartz CBS but even so it was noted on a very large $E$. obliqua log outside of the plot area but still within the CBS coupe. Postia subcaesia was the only heart-rot fungus found on small diameter wood. This fungus usually forms small fruit bodies, and a small fungus shouldn't require a large spatial domain, according to Rayner \& Boddy (1988). Similarly, the small fruit bodies of Skeletocutis nivea, Gloeoporus taxicola and Junghuhnia rhinocephala were found only on small or medium diameter wood, with the last species being confined to $P$. apetala. In Tasmania, J. rhinocephala has not yet been found on any other wood species, although in the Melbourne Herbarium (MEL) there are collections of it occurring on Acacia species. Four Stereum species, viz. $S$. ostrea, $S$. illudens, $S$. mugosum and S. hirsutum, were absent from large diameter wood in a high decay class. This is consistent with their known existence as latent invaders of sapwood and as some of the first fungi to appear on freshly downed wood. Galerina patagonica was predominantly found on small and medium diameter wood in the medium and high decay classes (as in Gates 2009), with only a single record on wood in a low decay class in the current study. Generally, however, the agarics, in particular the majority of the Mycena species, were spread across all wood diameter sizes and decay stages as observed by McMullan-Fisher (2008) and Gates (2009). A notable exception is $M$. subgalericulata which commonly fruits on large diameter living $E$. obliqua trees (Grgurinovic 2003) and continues fruiting on the fallen large diameter wood. Species very commonly found in old E. obliqua forests, such as Pluteus spp., Pleurotus purpureo-olivaceus, Plectania campylospora, Psilocybe brunneoalbescens, Hypoxylon bovei var. microsporum, Fomes hemitephrus and Tyromyces merulinus were not observed. This could be related to the short duration of the study, the small area surveyed or, in the case of the CBS plots, the lack of biological legacies.

\section{Implications for sustainable forestry management}

The results of this study can assist in developing protocols for sustainable forestry management in Tasmania. The current silviculture process of CBS removes large living trees which would eventually end up being large dead wood in the natural cycle of a wet $E$. obliqua forest. Wildfire disturbance being non-stand replacing in these forests (Alcorn et al. 2001, Turner et al. 2009) and at intervals of ca. three fires per century leaves either large stags, which are the next input of large dead wood, or living trees which are not killed by the fire. Our results show that there is a number of species of macrofungi (e.g., Australoporus tasmanicus and Ganoderma australe) which are only found fruiting on large diameter wood. This suggests that biodiversity of a predisturbance stand (as measured using fruit bodies) can be maintained in a 4.3-year-old forest, irrespective of whether it is regenerating after CBS silviculture or as a result of wildfire, providing there is sufficient large dead wood remaining after disturbance and that conditions are conducive to fruit body formation. This study could also assist in assessing the impact of the currently trialled alternative silviculture treatment to CBS in southern Tasmania, i.e. ARN, where "islands" of predisturbance habitat are retained to maintain biodiversity. The removal of all dead wood for biofuel could affect wood-inhabiting fungi; however; it is not known how much dead wood is necessary to retain in each decay stages and size class. The important point from this study is that retaining dead wood of all sizes and decay stages is necessary to maintain wood-inhabiting macrofungal diversity irrespective of whether it is a wildfire or a silviculture disturbance and should be part of sustainable forestry management protocols for the wet $E$. obliqua forests of southern Tasmania.

\section{CONCLUSIONS}

We conclude that:

- Dead wood of different sizes and stages of decay is a substrate for a rich and diverse assemblage of macrofungal species, supporting the finding of Gates (2009).

- A short-term study in these forests, such as the current one, can provide informative data.

- The presence of Pomaderris apetala, which was very abundant at the Edwards Rd plots but very sparse at the Hartz Rd plots, significantly influenced the macrofungal species assemblages, supporting a suite of species not found on other substrates.

- The low number of macrofungal species fruiting on Nothofagus is surprising, in view of the importance of that genus in New Zealand and South America as a substrate for wood-inhabiting fungi.

- The results of this study on wood-inhabiting macrofungi complement those of Gates et al. (2005, 2011c), adding an age since wildfire ( 43 years) not considered in the earlier studies. It also had anthropogenic disturbance as a comparison.

- Further studies in forests at different ages of regeneration are needed before and after both natural and anthropogenic disturbance to obtain a better picture of the effects of disturbance on macrofungal diversity in these forests. 


\section{ACKNOWLEDGEMENTS}

Funding from the Cooperative Research Centre for Forestry covered the costs of travel to the field plots. We thank Julian Geise 1 and Lily Pearce for their assistance with the fieldwork. The comments and suggestions of two anonymous referees were very useful and were heeded in preparing the revised versio $n$ of the manuscript.

\section{REFERENCES}

Alcom, P.J., Dingle, J.K. \& Hickey, J.E. 2001: Age and stand structure in a multi-aged wet eucalypt forest at the Warra silvicultural systems trial. Tasforests 13: 245-259.

Anderson, M.J., Gorley, R.N. \& Clarke, K.R. 2008: PERMANOVA+ for PRIMER: Guide to Software and Statistical Methods. The University of Auckland, Department of Statistics, Auckland, and PRIMER-E Ltd, Plymouth: $214 \mathrm{pp}$.

Arnolds, E. 2001: The future of fungi in Europe: threats, conservation and management. In Moore, D., Nauta, M.M., Evans, S.E. \& Rotheroe, M. (eds): Fungal Conservation: Issues and Solutions. Cambridge University Press, Cambridge: 64-50.

Bader, P., Jansson, S. \& Jonsson, B.G. 1995: Wood-inhabiting fungi and substratum decline in selectively logged boreal spruce forests. Biological Conservation 72: 355-362.

Bougher, N.L., Fuhrer, B.A. \& Horak, E. 1994: Taxonomy and biogeography of Australian Rozites species mycorrhizal with Nothofagus and Myrtaceae. Australian Systematic Botany 7: 353-375.

Bray, J.R. \& Curtis, J.T. 1957: An ordination of the upland forest communities of southern Wisconsin. Ecological Monographs 27: 325-349.

Browning, B.J., Jordan, G.J., Dalton, P.J., Grove, S.J., Wardlaw, T.J. \& Turner, P.A.M. 2010: Succession of mosses, liverworts and ferns on coarse woody debris, in relation to forest age and log decay in Tasmanian wet eucalypt forest. Forest Ecology and Management 260: 1896-1905.

Buchanan, P.K., Clinton, P.W. \& Allen, R.B. 2001: Dead wood in the forest - alive and dynamic! New Zealand Journal of Forestry: 40-42.

Burns, A. \& Conran, J.G. 1997: The phenology of macrofungi in relation to autumn rainfall in the Adelaide Hills. Muelleria 10: 95-109.

Carpenter, R.J. \& Pole, M. 1995: Eocene plant fossils from the Lefroy and Cowan paleodrainages, Western Australia. Australian Systematic Botany 8: 1107-1154.

Christensen, M., Heilmann-Clausen, J., Walleyn, R. \& Adamcik, S. 2004: Wood-inhabiting fungi as indicators of nature value in European beech forests. In Marchetti, M. (ed.): Monitoring and Indicators of Forest Biodiversity in Europe - from Ideas to Operationality, EFI Proceedings No. 51: $229-237$.

Clarlke, K.R. \& Gorley, R.N. 2006: PRIMER v6: User Manuall Tutorial. PRIMER-E Ltd, Plymouth: 192 pp.

Colwell, R.K. 2005: EstimateS: statistical estimation of species richness and shared species from samples. Version 7.5 .

Czederpiltz, D.L.L., Stanosz, G.R. \& Burdsall, H.H. 1999: Forest management and the diversity of wood-inhabiting fungi. McIlvainea 14: 34-45.

Esseen, P.-A., Ehnström, B., Ericson, L. \& Sjöberg, K. 1997: Boreal forests. Ecological Bulletins 46: 16-47.

Fryar, S.C., Kirby, G.C. \& Hyde, K.D. 1999: Species abundance patterns of two wood decay basidiomycete communities. Fungal Diversity 3: 39-56.

Gates, G.M. 2009: Coarse woody debris, macrofungal assemblages, and sustainable forest management in a Eucalyptus obliqua forest of southern Tasmania. Unpublished PhD thesis,
University of Tasmania, Hobart.

Gates, G.M. \& Ratkowslky, D.A. 2009: Comparing indigenous and European-based weather concepts for predicting macrofungal activity in Tasmania. Australasian Mycologist 28: $36-42$.

Gates, G.M., Ratkowsky, D.A. \& Grove, S.J. 2005: A comparison of macrofungi in young silvicultural regeneration and mature forest at the Warta LTER Site in the southern forests of Tasmania. Tasforests 16: 127-152.

Gates, G.M., Ratkowsky, D.A. \& Grove, S.J. 2009: Aggregated retention and mactofungi, a case study from the Warra LTER Site, Tasmania. Tasforests 18: 33-54.

Gates, G.M., Mohammed, C., Ratkowsky, D.A., Wardlaw, T. \& Davidson, N.J. 2011a: Diversity and ecology of epigeous ectomycorrhizal macrofungal assemblages in a native eucalypt forest in Tasmania, Australia, Fungal Ecology 4: 290-298.

Gates, G.M., Mohammed, C., Wardlaw, T., Davidson, N.J. \& Ratkowsky, D.A. 2011 b: Diversity and phenology of the macrofungal assemblages supported by litter in a tall, wet Eucalyptus obliqua forest of southern Tasmania, Australia. Fungal Ecology 4: 68-75.

Gates, G.M., Mohammed, C., Wardlaw, T., Ratkowsky, D.A. \& Davidson, N.J. 2011c: The ecology and diversity of woodinhabiting macrofungi in a native Eucalyptus obliqua forest of southern Tasmania, Australia. Fungal Ecology 4: 56-67.

Gilbert, J.M. 1959: Forest succession in the Florentine Valley, Tasmania. Papers and Proceedings of the Royal Society of Tasmania 93: 129-151.

Grgurinovic, C.A. 2003: The Genus Mycena in South-Eastern Australia. Fungal Diversity Press, Hong Kong: $329 \mathrm{pp}$.

Harmon, M.E., Sexton, J., Caldwell, B.A. \& Carpenter, S.E. 1994: Fungal sporocarp mediated losses of Ca, Fe, K, Mg, $\mathrm{Mn}, \mathrm{N}, \mathrm{P}$, and $\mathrm{Zn}$ from conifer logs in the early stages of decomposition. Canadian Journal of Forest Research 24: 1883-1893.

Heilmann-Clausen, J. \& Christensen, M. 2005: Wood-inhabiting macrofungi in Danish beech-forests - conflicting diversity patterns and their implications in a conservation perspective. Biological Conservation 122: 633-642.

Heilmann-Clausen, J. \& Vesterholt, J. 2008: Conservation: selection criteria and approaches. In Boddy, L., Franleland, J.C. \& van West, P. (eds): Ecology of Saprotrophic Basidiomycetes. Academic Press, London: 325-347.

Hickey, J.E., Neyland, M.G. \& Bassett, O.D. 2001: Rationale and design for the Warra silvicultural systems trial in wet Eucalyptus obliqua forests in Tasmania. Tasforests $\mathbf{1 3}$ : 155-182.

Hilton, R.N., Malajczulk, N. \& Pearce, M.H. 1989: Larger fungi of the jarrah forest: an ecological and taxonomic survey. In Dell, B., Havel, J.J. \& Malajczuk, N. (eds): The Jarrab Forest. A Complex Mediterranean Ecosystem. Kluwer Academic Publishers, Dordrecht, The Netherlands: 89-109.

Holland, J.D., Bert, D.G. \& Fahrig, L. 2004: Determining the spatial scale of species' response to habitat. Bioscience 54: 227-233.

Hopkins, A.J.M., Glen, M., Grove, S.J., Wardlaw, T.J. \& Mohammed, C.L. 2011: Wood-inhabiting fungi found within living Eucalyptus obliqua trees in southern Tasmania: Australasian Mycologist 29: 37-46.

Jackson, W.D. 1968: Fire and the Tasmanian flora. In Tasmanian Year Book No. 2, Commonwealth Bureau of Census and Statistics, Government Printer Hobart, Tasmania: 50-55.

Jonsson, B.G., Kruys, N. \& Ranius, T. 2005: Ecology of species living on dead wood - lessons for dead wood management. Silva Fennica 39: 289-309.

Kirkpatrick, J.B. \& Backhouse, S. 1981: Native Trees of Tasmania. Pandani Press, Hobart: 135 pp.

Komonen, A. 2001: Structure of insect communities inhabiting old-growth forest specialist bracket fungi. Ecological 
Entomology 26: 63-75.

Lindenmayer, D.B. \& McCarthy, M.A. 2002: Congruence between natural and human forest disturbance - an Australian perspective. Forest Ecology and Management 155: 319-335.

McKenzie, E.H.C., Buchanan, P.K. \& Johnston, P.R. 2000: Checklist of fungi on Nothofagus species in New Zealand. New Zealand Journal of Botany 38: 635-720.

McMullan-Fisher, S.J.M. 2008: Surrogates for cryptogam conservation - association between mosses, macrofungi, vascular plants and environmental variables. Unpublished $\mathrm{PhD}$ thesis, University of Tasmania, Hobart.

McMullan-Fisher, S.J.M., May, T.W. \& Keane, P.J. 2002: The macrofungal community and fire in a Mountain Ash forest in sourhern Australia. In Hyde, K.D. \& Jones, E.B.G. (eds) Fungal Succession. Fungal Diversity Press, Hong Kong: $57-76$.

Packham, J.M., May, T.W., Brown, M.J., Wardlaw, T.J. \& Mills, A.K. 2002: Macrofungal diversity and community ecology in mature and regrowth wet eucalypt forest in Tasmania: A multivariate study. Austral Ecology 27: 149-161.

Pavoir-Smith, K. 1960: 'The fruiting-bodies of macrofungi as habitats for beetles of the family Ciidae (Coleoptera). Oikos 11(1): 43-71.

Penttilä, R., Lindgren, M., Miettinen, O., Rita, H. \& Hanski, I. 2006: Consequences of forest fragmentation for polyporous fungi at two spatial scales. Oikos 114: 225-240.

Pielou, D.P. \& Verma, A.N. 1968: The arthropod fauna associated with the birch bracket fungus, Polyporus betulinus, in eastern Canada. The Canadian Entomologist 100: 1179-1 199.

Public Land Use Commission 1996: Tasmanian-Commonwealth Regional Forest Agreement Background Report, Part C. Environment and Heritage Report, Volume 1. Tasmanian Public Land Use Commission, Hobart, Tasmania: xx pp.

Rajchenberg, M. 2006: Los Poliporos (Basidiomycetes) de los Bosques Andino Patagónicos de Argentina. J.Cramer, Berlin: 300 pp.

Rayner, A.D.M. \& Boddy, L. 1988: Fungal Decomposition of Wood: Its biology and ecology. John Wiley \& Sons Ltd, Chichester: 587 pp.
Renvall, P. 1995: Community structure and dynamics of woodrotting Basidiomycetes on decomposing conifer trunks in northern Finland. Karstenia 35: 1-51.

Robinson, R.M., Mellican, A.E. \& Smith, R.H. 2008: Epigeous macrofungal succession in the first five years following a wildfire in karri (Eucalyptus diversicolor) regrowth forest in Western Australia. Austral Ecology 33: 807-820.

Robinson, R.M., Pearce, K. \& Smith, R.H. 2003: Macrofungi. Forestcheck Report of Progress 2002-2003, CALM, Science Division: 42-67.

Robinson, R.M. \& Tunsell, V.L. 2007: A list of macrofungi recorded in buint and unburnt Eucalyptus diversicolor regrowth forest in southwest of Western Australia: 19982002. Conservation Science Western Australia 6: 75-96.

Schigel, D.S. 2007: Fleshy fungi of the genera Amillaria, Pleurotus, and Grifola as habitats of Coleoptera. Karstenia 47: 37-48.

Turner, P.A.M., Balmer, J. \& Kirkpatrick, J.B. 2009: Standreplacing wildfires? The incidence of multi-cohort and single-cohort Eucalyptus regnans and E. obliqua forests in southern Tasmania. Forest Ecology and Management 258: 366-375.

Vogt, K.A., Edmonds, R.L. \& Grier, C.C. 1981: Biomass and nutrient concentrations of sporocarps produced by mycorrhizal and decomposer fungi in Abies amabilis stands. Oecologia 50: 170-175.

Watling, R. 2005: Fungal conservation: some impressions - a personal view. In Dighton, J., White, J.F. \& Oudemans, P. (eds): The Fungal Community: Its Organization and Role in the Ecosystem. Taylor and Francis, Boca Raton: 881-896.

Wells, P. \& Hickey, J. 1999: Wet sclerophyll, mixed and swamp forest. In Reid, J.B., Hill, R.S., Brown, M.J. \& Hovenden, M.J. (eds): Vegetation of Tasmania. Australian Biological Resources Study, Canberra: 224-243.

Wiltshire, R.J.E. \& Jordan, G.J. 2009: TreeFlip - Life-size guide to the trees of Tasmania. University of Tasmania, Hobart, Australia.

Wiltshire, R.J.E. \& Potts, B.M. 2007: EucaFlip - Life-size guide to the eucalypts of Tasmania. University of Tasmania, Hobart, Australia.

(accepted 11 November 2011 